\title{
A Paracoccidioides brasiliensis Polysaccharide Having Granuloma-inducing, Toxic and Macrophage-stimulating Activity
}

\author{
By CÉLIO L. SILVA* AND RAQUEL A. FAZIOLI \\ Department of Parasitology, Microbiology and Immunology, School of Medicine of \\ Ribeirào Preto, University of São Paulo, 14100 Ribeirão Preto, SP, Brazil
}

(Received 25 September 1984; revised 20 November 1984)

\begin{abstract}
The occurrence of a polysaccharide fraction of Paracoccidioides brasiliensis cell wall with toxic, granuloma-inducing and macrophage-stimulating activities was demonstrated. After fractionation of the lipid-extracted wall with $1 \mathrm{M}-\mathrm{NaOH}$, three fractions were obtained: (1) an alkaliinsoluble fraction; (2) an alkali-soluble, acid-insoluble fraction and (3) an alkali-soluble, acidsoluble fraction. When the three fractions were injected into mice only fraction (1) was able to induce chronic lung inflammation, causing a marked loss in body weight and death at a dose of $6 \mathrm{mg}$ per animal. Analysis of the stimulation of peritoneal macrophages of mice (measured by cell spreading on glass) after intraperitoneal injection of fraction 1 showed that $75 \%$ of the cells were able to spread even $20 \mathrm{~d}$ after inoculation.
\end{abstract}

\section{INTRODUCTION}

Paracoccidioidomycosis or South American blastomycosis is the most widespread systemic mycosis in South America (Mackinnon, 1970) and is characterized by a suppurative and granulomatous inflammatory reaction. Many aspects of the disease and its agent (Paracoccidioides brasiliensis) are still unknown. Among the various factors isolated from this pathogenic fungus that may determine its pathogenicity, lipids and the cell wall polysaccharide deserve special mention (San-Blas, 1982). Silva (1985) attempted to isolate a fraction from $P$. brasiliensis yeast cells that may be responsible for the pathological responses observed in paracoccidioidomycosis. A lipid fraction obtained from the cells induces pulmonary granulomatous reactions in mice. We have investigated the possibility that the inflammatory reactions produced in infections caused by $P$. brasiliensis may be attributed not only to lipid components but also to the cell wall polysaccharide.

\section{METHODS}

Fungal strain and culture conditions. Paracoccidioides brasiliensis $05 / 135$ was obtained from Dr Arlete M. Cury, Faculty of Pharmaceutical Sciences, University of São Paulo, Brazil. This strain was originally isolated from a paracoccidioidomycosis patient and has been maintained on Sabouraud's dextrose agar. It was cultured at $35^{\circ} \mathrm{C}$ for $20 \mathrm{~d}$ in medium containing $20.0 \mathrm{~g}$ glucose, $10.0 \mathrm{~g}$ peptone and $1.0 \mathrm{~g}$ yeast extract in 1 litre distilled water. The cells were then harvested, washed seven times with distilled water and freeze-dried.

Preparation of walls. The freeze-dried yeast cells were disrupted by ultrasonic vibration at $200 \mathrm{~W}$ for $3 \mathrm{~min}$; this process was repeated six times. A high degree of disruption was always observed by phase-contrast microscopy. The walls were collected and washed with distilled water by centrifugation at $5000 \mathrm{~g}$ for $5 \mathrm{~min}$. Washing was continued until phase-contrast microscopy indicated that the wall suspensions were free of undisrupted cells and cytoplasmic components. The freeze-dried wall samples were submitted to lipid extraction by soaking in chloroform/methanol $(2: 1, \mathrm{v} / \mathrm{v})$ with stirring at room temperature for $2 \mathrm{~h}$. The extract was separated by centrifugation at $5000 \mathrm{~g}$ for $5 \mathrm{~min}$ and the insoluble residue was re-extracted three more times as described.

Abbreviations: i.p., intraperitoneal(ly); i.v., intravenous(ly). 
Partial fractionation of walls. This was done by alkaline extraction as described by Kanetsuna et al. (1972). Briefly, walls were suspended in $1 \mathrm{M}-\mathrm{NaOH}\left(10 \mathrm{mg} \mathrm{ml}^{-1}\right)$ and gently stirred at room temperature for $1 \mathrm{~h}$. After centrifugation at $5000 \mathrm{~g}$ for $10 \mathrm{~min}$, the supernatant was collected, and the procedure repeated four times, combining all the supernatants. The alkali-insoluble sediment was washed with water until it reached $\mathrm{pH} 7$ and then with ethanol, followed by acetone, and diethyl ether. The resulting white powder was called fraction F1. The pooled supernatants were neutralized with acetic acid and left to stand overnight at $4{ }^{\circ} \mathrm{C}$, after which a precipitate had formed. The suspension was then centrifuged as before. The precipitate and the supernatant were collected, dialysed separately against distilled water and freeze-dried, yielding fractions F2 (alkali-soluble and precipitable with acid) and F3 (alkali-soluble and nonprecipitable with acid), respectively.

Trypsin-treatment of alkali-insoluble fraction F1. Fraction F1 was suspended in $0 \cdot 1 \mathrm{M}$-phosphate buffer containing trypsin $\left(100 \mu \mathrm{g} \mathrm{ml}^{-1}\right)$ and incubated in a shaking water bath for $3 \mathrm{~h}$ at $37^{\circ} \mathrm{C}$. The suspension was then centrifuged at $17000 \mathrm{~g}$ for $10 \mathrm{~min}$, the supernatant was discarded, and the pellet was washed repeatedly with distilled water until the supernatant solution showed no absorbance at $280 \mathrm{~nm}$, indicating removal of residual enzyme.

Acid hydrolysis of alkali-insoluble fraction $\mathrm{Fl}$. Fraction $\mathrm{Fl}$ was hydrolysed with $6 \mathrm{M}-\mathrm{HCl}$ at $110^{\circ} \mathrm{C}$ for $16 \mathrm{~h}$. The $\mathrm{HCl}$ was removed from the remaining portion of the hydrolysates by evaporation in vacuo over silica gel and $\mathrm{NaOH}$ pellets. The residue was dissolved in a small volume of water and passed through a $1 \times 10 \mathrm{~cm}$ column containing Amberlite IR $120\left(\mathrm{H}^{+}\right.$form) and Amberlite IR $45\left(\mathrm{OH}^{-}\right.$form) with water as eluent. The desalted solution was concentrated by freeze-drying.

Analytical procedure. Qualitative analyses for monosaccharides and amino acids were done by paper chromatographic procedures outlined previously (Kanetsuna et al., 1969). Neutral sugars and amino sugars were visualized with alkaline silver nitrate reagent (Trevelyan et al., 1950) and Elson-Morgan reagent, respectively (Partridge, 1948). Amino acids were visualized with ninhydrin reagent.

Animals. Male Balb/c mice 4 to 6 weeks old weighing 20 to $25 \mathrm{~g}$ were used.

Evaluation of lung and spleen inflammatory reaction. The inflammatory property of wall fractions F1, F2 and F3 was tested by histological analysis and by recording the weight of the lungs and spleen after injecting mice with $200 \mu \mathrm{g}$ of each preparation in $0.1 \mathrm{ml} 0.85 \%$ saline through the retro-orbital venous plexus. For histological analysis, the animals were anaesthetized with ether and killed by exsanguination. Their lungs were fixed by the infusion of $2 \mathrm{ml}$ Bouin's fixative into the exposed trachea. The fixed organs were sectioned through the hilus and histological sections were made of different areas of both lungs. For recording the lung and spleen weight, the animals (five per group) were killed by cervical dislocation, and their lungs and spleen were removed, trimmed of extraneous tissue, rinsed in saline, blotted, and weighed.

Toxicity. The toxicity of wall fractions was evaluated by intraperitoneal (i.p.) injection of each preparation (6 $\mathrm{mg}$ in $0.85 \%$ saline) into a group of 10 mice and recording loss of body weight and mortality.

Evaluation of macrophage stimulation. Peritoneal cells were collected from mice previously given an i.p. injection of $200 \mu \mathrm{g}$ of fraction F1, F2 or F3 in $0.2 \mathrm{ml} 0.85 \%$ saline, or saline alone, and killed by cervical dislocation. Peritoneal fluid was withdrawn with a Pasteur pipette. After harvesting by centrifugation $(800 \mathrm{~g} ; 5 \mathrm{~min})$ the cells were washed in culture medium and seeded at a concentration of $5 \times 10^{5}$ cells in $0.25 \mathrm{ml}$ culture medium on $18 \times 22 \mathrm{~mm}$ glass coverslips. The culture medium was 199 medium (Flow Laboratories) containing $5 \%(\mathrm{v} / \mathrm{v})$ heatinactivated foetal calf serum and $1 \%(\mathrm{w} / \mathrm{v})$ glutamine. The cells were allowed to adhere for $40 \mathrm{~min}$ at $34{ }^{\circ} \mathrm{C}$, and then nonadherent cells were removed by washing the coverslips with 199 medium. The coverslips were placed in plastic Petri dishes, covered with 199 medium and incubated at $34^{\circ} \mathrm{C}$ for $1 \mathrm{~h}$. After incubation the cell layers were washed three times with $0.85 \%$ saline, fixed with $2.5 \%(\mathrm{v} / \mathrm{v})$ glutaraldehyde and water-mounted for phase-contrast microscopy $(400 \times)$. Macrophage stimulation was evaluated by recording the percentage of the total adherent peritoneal cells that spread onto glass coverslips.

Statistical analysis. Student's $t$ test was used.

\section{RESULTS}

Fractions F1, F2 and F3 obtained from yeast cell walls of $P$. brasiliensis after alkali treatment were assayed for toxicity in mice, as measured by loss of body weight and mortality after i.p. inoculation of a single dose of $6 \mathrm{mg}$. The alkali-insoluble fraction F1 was toxic, causing wasting symptoms and rapid loss of body weight (Fig. 1). Weight was significantly $(P<0.05)$ decreased at $8 \mathrm{~d}$, before any mice had died. The difference was even greater $(P<0.01)$ at $20 \mathrm{~d}$, just after the onset of mortality in the injected group. Autopsy of animals injected with fraction F1 revealed evidence of peritonitis with an inflammatory exudate, massive adhesions of all organs of the upper peritoneal cavity, numerous granulomas and splenomegaly. Mice injected with alkali-soluble fractions F2 and F3 showed no signs of illness and gained weight normally (Fig. 1). 


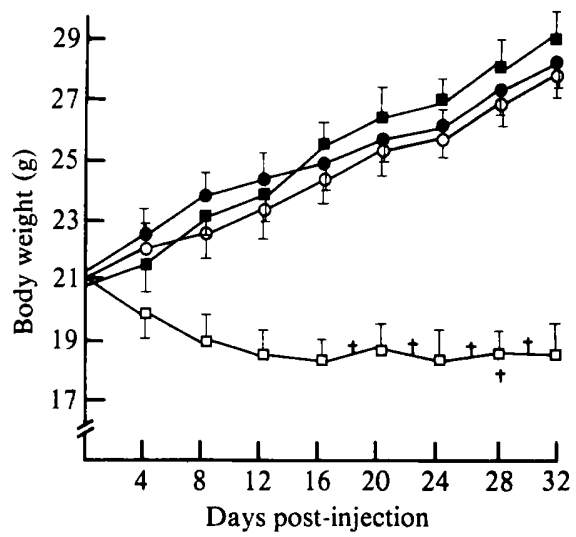

Fig. 1. Mean body weight ( $\pm \mathrm{SD}$ ) of four groups of ten mice at various times after i.p. injection (in $0.85 \%$ saline) of a single dose of $6 \mathrm{mg}$ of fraction $\mathrm{F} 1(\square) ; 6 \mathrm{mg}$ of fraction $\mathrm{F} 2(\mathrm{O}) ; 6 \mathrm{mg}$ of fraction F3 (O) or saline alone $(\square)$. Each cross $(\dagger)$ represents the death of one mouse.

Table 1. Influence of cell wall fractions on the weight of lungs and spleen in mice

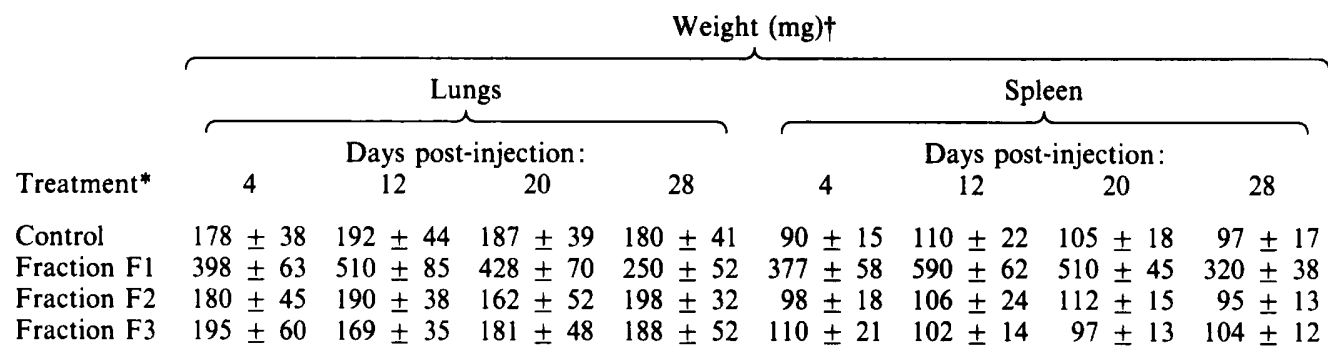

* Each fraction $(200 \mu \mathrm{g})$ was given intravenously in $0.1 \mathrm{ml}$ saline (the control group was injected with saline alone).

$\dagger$ Given as arithmetic mean \pm SD of five mice at each time point.

When these animals were killed $30 \mathrm{~d}$ after inoculation, no pathological changes were detected. Trypsin-treated fraction F1 was lethal for mice at a dose of $6 \mathrm{mg}$. Acid-treated fraction F1 was non-toxic.

Thin-layer chromatography of an acid hydrolysate of fraction F1 showed the presence of glucose as the main neutral sugar, although traces of galactose were present. Amino acids were present in small amounts. It was not determined whether they were present separately or bound in the form of glycoproteins. Glucosamine was also detected.

The inflammatory reaction induced by fractions F1, F2 and F3 in lung and spleen was determined by recording the weight of the organs and by histological analysis of the tissues 2,4 , 8,16 and $32 \mathrm{~d}$ after intravenous (i.v.) inoculation into mice of $200 \mu \mathrm{g}$ of each preparation. Table 1 shows that by the fourth day a significant increase had occurred in the lung and spleen weight of animals injected with fraction F1 in relation to the weights obtained for animals inoculated with fractions F2 and F3 and for those killed immediately after inoculation (time zero). Histological analysis of the lungs of animals inoculated with fraction F1 revealed intense and focal infiltrates of polymorphonuclear cells. Stabilization of the cell infiltrate occurred on the fourth day in the lungs and spleens of animals inoculated with fraction F1, and large numbers of polymorphonuclear and mononuclear cells were still present between days 4 and 8 (Fig. 2). On day 16, however, the small infiltrates observed were composed predominantly of large, tightly packed mononuclear cells, with a tendency to stack in a more organized fashion and to form epithelioid-type cells. No inflammatory cell infiltrates were observed in lungs and spleens removed on day 32 . 


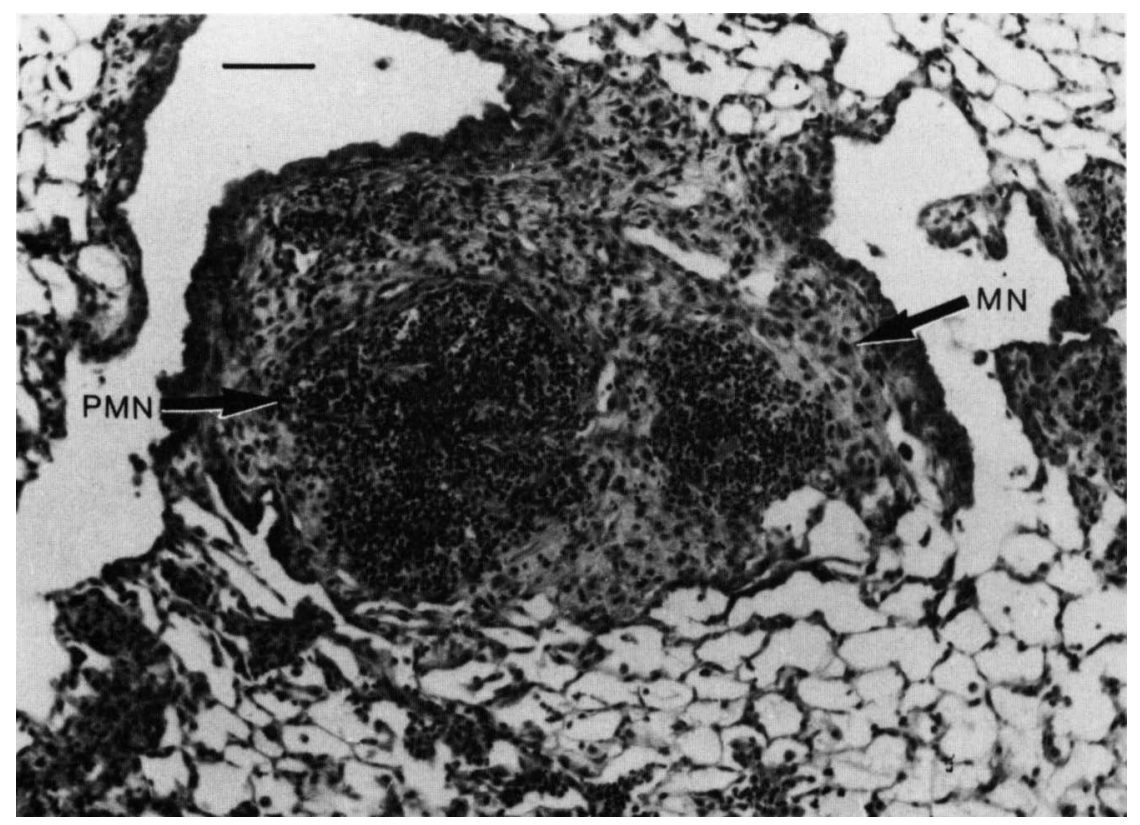

Fig. 2. Lung inflammatory response $4 \mathrm{~d}$ after intravenous injection of $200 \mu \mathrm{g}$ of fraction F1. Note intense and focal infiltrates of polymorphonuclear (PMN) and mononuclear (MN) cells in the alveolar interstitium (arrowed). The bar represents $100 \mu \mathrm{m}$.

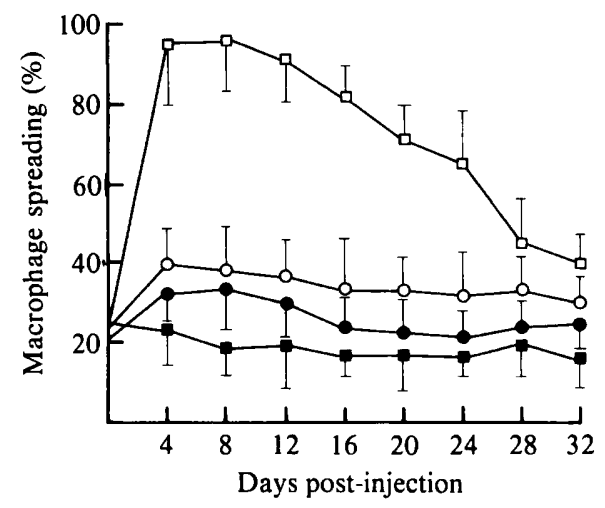

Fig. 3. Percentage of peritoneal macrophages that spread onto glass coverslips after i.p. injection into mice (in $0.2 \mathrm{ml} 0.85 \%$ saline) of $200 \mu \mathrm{g}$ of fraction $\mathrm{F} 1(\square) ; 200 \mu \mathrm{g}$ of fraction $\mathrm{F} 2(\mathrm{O}) ; 200 \mu \mathrm{g}$ of fraction F3 (O) and saline alone ( $\square$ ). Values are means \pm SD of five animals for each time point.

Fractions F1, F2 and F3 showed different abilities to stimulate macrophages in the peritoneal cavity of mice after i.p. inoculation of $200 \mu \mathrm{g}$ in $0.2 \mathrm{ml}$ saline (Fig. 3). The greatest stimulation by fraction F1 occurred about $4 \mathrm{~d}$ after inoculation, when about $95 \%$ of the cells spread on the slide. In contrast, fractions $\mathrm{F} 2$ and $\mathrm{F} 3$ did not significantly stimulate adhering macrophages to spread on the slide surface in comparison with the control (saline).

\section{DISCUSSION}

The mechanisms whereby $P$. brasiliensis produces disease in man are still unclear. The data presented here support the idea that granuloma formation depends on the polysaccharide composition of the agent which triggers attraction and concentric organization of polymorphonuclear cells and macrophages. These data not only indicate the granuloma-forming capacity of 
the polysaccharide fraction but also show that it induces weight loss and mortality of mice, a fact which argues strongly for the participation of this fraction in the genesis and persistence of the inflammatory reaction in paracoccidioidomycosis.

Mice inoculated i.v. with fraction Fl responded with a marked enlargement of the lungs and spleen. Histological analysis showed that these organs were populated by an intense polymorphonuclear cell infiltrate during the early stages after inoculation of fraction $F 1$, by polymorphonuclear and mononuclear cells at the middle stage and by mononuclear cells during the final phase of the inflammatory process.

A rapid decrease in body weight was observed within a few days after i.p. inoculation of fraction F1. Weight loss was an easy parameter to follow and was a predictor of ultimate mortality even when animals were active and appeared otherwise healthy.

Like many other pathogenic fungi, $P$. brasiliensis is dimorphic, developing a yeastlike form ( $\mathrm{Y}$ form) at $37^{\circ} \mathrm{C}$ and easily converted to the mycelial form ( $M$ form) when the temperature is shifted to $23{ }^{\circ} \mathrm{C}$. The process is readily reversible and temperature is the only factor known to affect dimorphism (Nickerson, 1948). The major constituents of the cell walls of both $\mathrm{Y}$ and $\mathrm{M}$ forms have been reported to be glucans, chitin and protein. The glucans were studied by Kanetsuna \& Carbonell (1970), and the results obtained from alkali-treated cell walls indicated that the glucans of the $\mathrm{Y}$ form mainly have an $\alpha$-linkage and those of the $M$ form have a $\beta$ linkage. The difference in glucans between the two forms has been considered an important factor for explaining thermal dimorphism and virulence (San-Blas, 1982).

Glucan, the polysaccharide portion of the cell wall of the yeast Saccharomyces cerevisiae, has long been known to stimulate the reticuloendothelial system, with macrophage proliferation (Wooles \& Di Luzio, 1964). Intraperitoneal inoculation into mice of fraction F1 isolated from $P$. brasiliensis yeast walls stimulated peritoneal macrophages (as measured by cell spreading on glass). The mechanism of this stimulation is unknown, although in a previous experiment we demonstrated that there also appears to be a marked enhancement of humoral and cell-mediated immune function.

The data presented in this paper clearly show that a polysaccharide component plays a fundamental role in infections caused by $P$. brasiliensis. Further characterization of the polysaccharide constituent responsible for the pathological reactions will be worthwhile.

\section{REFERENCES}

Kanetsuna, F. \& Carbonell, L. M. (1970). Cell wall glucans of the yeast and mycelial forms of Paracoccidioides brasiliensis. Journal of Bacteriology 101, 675680.

Kanetsuna, F., Carbonell, L. M., Moreno, R. E. \& Rodriguez, J. (1969). Cell wall composition of the yeast and mycelial forms of Paracoccidioides brasiliensis. Journal of Bacteriology 97, 1036-1041.

Kanetsuna, F., Carbonell, L. M., Azuma, I. \& Yamamura, Y. (1972). Biochemical studies on the thermal dimorphism of Paracoccidioides brasiliensis. Journal of Bacteriology 110, 208-218.

Mackinnon, J. M. (1970). On the importance of South American blastomycosis. Mycopathologia 41, 187193.

NiCkERSON, W. J. (1948). Enzymatic control of cell division in micro-organisms. Nature, London 162, 241-245.

Partridge, S. M. (1948). Filter-paper partition chro-

matography of sugars. I. General description and application to the qualitative analysis of sugars in apple juice, egg white and foetal blood of sheep. Biochemical Journal 42, 238-250.

San-Blas, G. (1982). The cell wall of fungal human pathogens : its possible role in host-parasite relationships. Mycopathologia 79, 159-184.

Silva, C. L. (1985). Granulomatous reaction induced by lipids isolated from Paracoccidioides brasiliensis. Transactions of the Royal Society of Tropical Medicine and Hygiene 79, (in the Press).

Trevelyan, W. E., Proctor, D. E. \& Harrison, J. S. (1950). Detection of sugars on paper chromatograms. Nature, London 166, 444-445.

Wooles, W. R. \& Di Luzio, N. R. (1964). The phagocytic and proliferative response of the reticuloendothelial system following glucan administration. Journal of the Reticuloendothelial Society 1, 160169. 